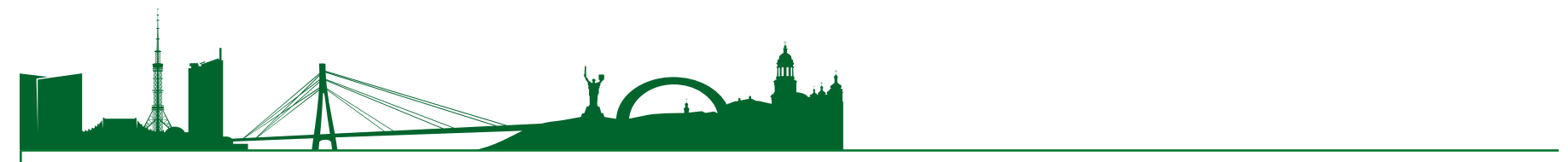

УДК 624.137.2; 24.131

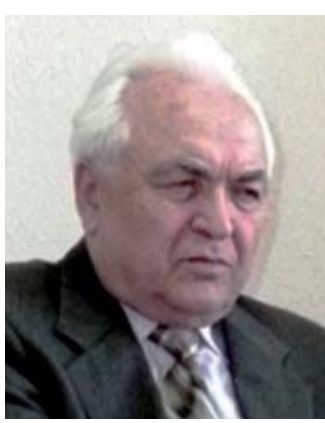

БIАЕУШ A.I.

Д-р технічних наук, проф. Інститут гідромеханіки НАН України, м. Київ, Україна, e-mail: Igmggs@ukr.net, тел.: + 38 (066) 794-37-84, ORCID: 0000-0002-7292-999X

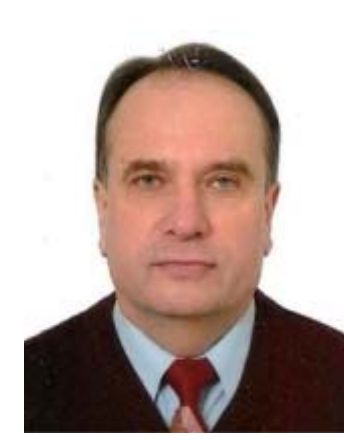

\section{КРИВОНОГ О.І.}

Канд. технічних наук, ст. науковий

Інститут співробітник, НАН України, м. Київ, Україна, e-mail: Igmggs@ukr.net, тел.: + 38 (097) 674-80-47, ORCID: 0000-0002-8435-3393

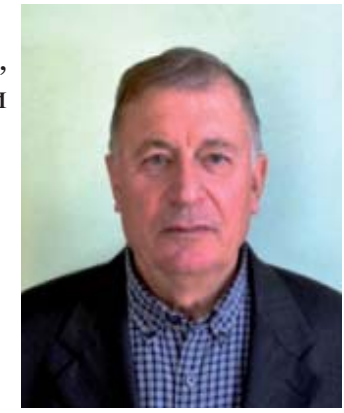

\section{ФРІДРІХСОН В.А.}

Канд. технічних наук, ст. науковий співробітник, Інститут гідромеханіки НАН України, м. Київ, Україна, e-mail: Igmggs@ukr.net, тел.: + 38 (067) 450-22-95,

ORCID: 0000-0003-4001-8646

\title{
АРМОВАНІ ГЕОСИНТЕТИЧНИМИ МАТЕРІАЛАМИ ГРУНТОВІ КОНСТРУКЦІЇ, ЩО СПРИЙМАЮТЬ ЗУСИААЯ НА ЗГИН
}

\section{АНОТАЦІЯ}

Дослідження роботи грунтових конструкцій, армованих геосинтетичними матеріалами, виконували експериментально на малорозмірних моделях і чисельним моделюванням 3 використанням програмного комплексу PLAXIS. Досліджували моделі конструкцій фундаментних подушок для зміцнення слабких основ і протизсувних споруд 3 метою підвищення стійкості схилів. Конструкції являють собою об'ємно замкнуті системи, міцність яких визначається їх геометрією, міцністю геосинтетичних матеріалів на розтяг і міцністю їх з'єднання, видом і щільністю заповнювача. Вони можуть розподіляти напруги по площі, сприймати зсувні навантаження грунту на схилі, виконувати функцію дренажу. Армована сітка розподіляє напруги по всій площі армування, що забезпечує збільшення несучої здатності основи фундаменту і зменшує його деформації. У свою чергу, геотекстиль виконує функцію розділяючого шару між грунтом основи і заповнювачем. 3 огляду на те, що геосітка працює на розтяг, а ущільнений наповнювач - на стиск, наближено можна вважати, що під дією зовнішнього навантаження армовані грунтові конструкції працюють як плита на пружній грунтовій основі.

Конструкції 3 оболонкою 3 міцних геосинтетичних матеріалів, що щільно заповнені щебе- нем, гравієм або відсівом, працюють на згин, розподіляючи вертикальні або горизонтальні навантаження по площі. В протизсувних спорудах такі конструкції передають зсувний тиск на стійкі грунти та виконують функції дренажу.

КАЮЧОВI CЛОBА: армовані конструкції, геосинтетичні матеріали, фундаментна подушка, стійкість схилів, утримуюча споруда.

\section{АРМИРОВАННЫЕ ГЕОСИНТЕТИЧЕСКИМИ МАТЕРИАЛАМИ ГРУНТОВЫЕ КОНСТРУК- ЦИИ, ВОСПРИНИМАЮЩИЕ УСИАИЯ НА ИЗГИБ}

БИЛЕУШ А.И. Д-р технических наук, проф., Институт гидромеханики НАН Украины,

г. Киев, Украина,

e-mail: igmggs@ukr.net,

тел.: + 38 (066) 794-37-84,

ORCID: 0000-0002-7292-999X

ФРИДРИХСОН В.А. Канд. технических наук, ст. научный сотрудник, Институт гидромеханики НАН Украины,

г. Киев, Украина,

e-mail: igmggs@ukr.net,

тел.: + 38 (067) 450-22-95,

ORCID: 0000-0003-4001-8646

КРИВОНОГ А.И. Канд. технических наук, ст. научный сотрудник, Институт гидромеханики 


\section{1 H}

НАН Украины,

г. Киев, Украина,

e-mail: igmggs@ukr.net,

тел.: + 38 (097) 674-80-47,

ORCID: 0000-0002-8435-3393

КРИВОНОГ В.В. Канд. технических наук, ст. научный сотрудник, Институт гидромеханики НАН Украины,

г. Киев, Украина,

e-mail: igmggs@ukr.net,

тел.: + 38 (097) 674-80-47,

ORCID: 0000-0002-3788-6947

\section{АННОТАЦИЯ}

Исследование работы грунтовых конструкций, армированных геосинтетическими материалами, выполняли экспериментально на малоразмерных моделях и численным моделированием с использованием программного комплекса PLAXIS. Исследовали модели конструкций фундаментных подушек для укрепления слабых оснований и противооползневых сооружений с целью повышения устойчивости склонов. Конструкции представляют собой объемно замкнутые системы, прочность которых определяется их геометрией, прочностью геосинтетических материалов на растяжение и прочностью их соединения, видом и плотностью заполнителя. Они могут распределять напряжения по площади, воспринимать сдвижные нагрузки грунта на склоне, выполнять функцию дренажа. Армирующая сетка распределяет напряжения по всей площади армирования, что обеспечивает увеличение несущей способности основания фундамента и уменьшает его деформации. В свою очередь, геотекстиль выполняет функцию разделяющего слоя между грунтом основания и заполнителем. Учитывая то, что геосетка работает на растяжение, а уплотненный наполнитель - на сжатие, приближенно можно считать, что под действием внешней нагрузки армированные грунтовые конструкции работают как плита на упругой грунтовой основе.

Конструкции с оболочкой из прочных геосинтетических материалов, которые плотно заполнены щебнем, гравием или отсевом, работают на изгиб, распределяя вертикальные или горизонтальные нагрузки по площади. В противооползневых сооружениях такие конструкции передают сдвижное давление на устойчивые грунты и выпол-няют функции дренажа.

КЛЮЧЕВЫЕ СЛОВА: армированные конструкции, геосинтетические материалы, фундаментная подушка, устойчивость склонов, удерживающее сооружение.

\section{GEOSYNTHETICS REINFORCED STRUCTURES THAT TAKE BENDING}

BILEUSH A.I. Dr., Prof., Institute of Hydromechanics of the National Academy of Sciences of Ukraine, Kyiv, Ukraine, e-mail: igmggs@ukr.net,

tel.: + 38 (066) 794-37-84,

ORCID: 0000-0002-7292-999X

FRIDRIHSON V.L. PhD, Senior Scientifist, Institute of Hydromechanics, National Academy of Sciences of Ukraine,

Kyiv, Ukraine,

e-mail: igmggs@ukr.net,

tel.: + 38 (067) 450-22-95,

ORCID: 0000-0003-4001-8646

KRYVONOG A.I. PhD, Senior Scientifist, Institute of Hydromechanics of the National Academy of Sciences of Ukraine,

Kyiv, Ukraine,

e-mail: igmggs@ukr.net,

tel.: + 38 (097) 674-80-47

ORCID: 0000-0002-8435-3393

KRYVONOG V.V. PhD, Senior Scientifist, Institute of Hydromechanics of the National Academy of Sciences of Ukraine,

Kyiv, Ukraine,

e-mail: igmggs@ukr.net,

tel.: + 38 (097) 674-80-47,

ORCID: 0000-0002-3788-6947

\section{ABSTRACT}

The behavior of geosynthetics reinforced soil structures was examined experimentally on small size models using numerical modeling at PLAXIS. The construction models of foundation footing for strengthening weak foundations and landslide protection structures were researched with the purpose of increasing stability of slopes. The constructions are three-dimensional closed systems, which strength is determined by their geometry, by the tensile strength of geosynthetics and by the strength of their joints, type and density of filler. Those can distribute stresses over the area, take the soil landslide forces on the slope, act as a drainage. Reinforced net distributes stress over the entire area of reinforcement, what leads to increasing bearing capacity of the foundation and reduces the deformation of that. Again, geotextile acts as a separating layer between the foundation and the filler. Given the fact that the geogrid is in tension and the compacted filler is in compression, it can be assumed that, under the influence of external load, the reinforced soil structures work as a plate on an elastic soil foundation.

Structures with coating made from durable geosynthetics, which are tightly filled with crushed stone, gravel or stone screening dust, work in bending, distributing vertical or horizontal loads over the area. These structures transmit the sliding pressure on stable soils and act as a drainage in antilandslide constructions.

KEY WORDS: reinforced structures, geosynthetics, foundation footing, stability of slopes, retaining structure. 


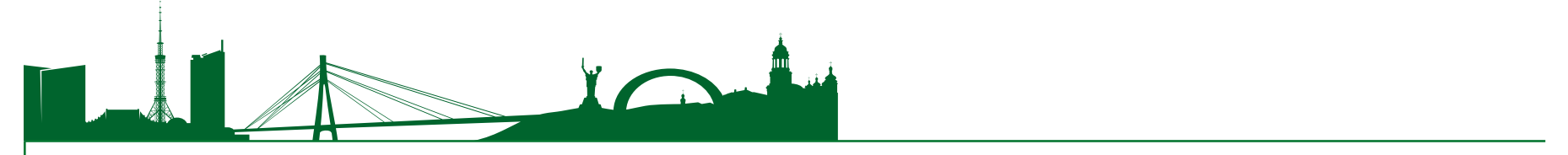

\section{АНАЛІЗ ПУБАІКАЦІЙ ТА ПОСТАНОВКА ЗАВДАННЯ}

За результатами аналізу літературних джерел можна констатувати, що ефективність армованої грунтової конструкції залежить від фізико-механічних показників матеріалу геосинтетиків, характеристик грунту та механізму зчеплення 3 ним [1-5]. Для збільшення зчеплення застосовують напівзамкнені і замкнені обойми (рис. 1). В таких конструкціях геотекстиль являє собою гнучку конструкцію і не сприймає зусиль на згин.

Для розрахунку грунтових конструкцій з застосуванням геосинтетичних матеріалів в світі використовують наступні методики.

1. Німецькі рекомендації щодо армування геосинтетиками (EBGEO) регламентують застосування матеріалів 3 міцністю > $30 \mathrm{\kappa H} /$ м. Вони дозволяють розрахувати зусилля в геосинтетичних матеріалах в повздовжньому та поперечному напрямках і описують виникнення арочного ефекту [6].

2. Британський стандарт не зв'язує форму арки i розподіл напружень з параметрами грунту i міцністю геосинтетичного матеріалу.

3. Російська методика не має обгрунтування появи арочного ефекту і розрахунків по міцності геосинтетичного матеріалу.

Робота грунтових конструкцій з геосинтетичними матеріалами може моделюватись у двовимірній чи тривимірній постановці, використовуючи програмні комплекси PLAXIS.

\section{ОСНОВНІ ЦІАІ ДОСАІДЖЕННЯ}

1. Дослідження роботи грунтових конструкцій 3 геосинтетичними матеріалами, що можуть сприймати зусилля на згин, за допомогою експериментальних та чисельних досліджень моделей конструкцій фундаментних подушок та протизсувних споруд для укріплення слабких основ та схилів.

2. Розробка розрахункових схем та залежностей для розрахунку на міцність запропонованих конструкцій.

\section{РЕЗУАЬТАТИ РОБОТИ ТА ÏХ ОБГРУНТУВАННЯ}

Запропонована авторами конструкція фундаментної подушки містить армуючу геосинтетичну сітку, нетканий захисно-фільтруючий синтетичний матеріал та заповнювач з щебеню, гравію або відсіву. Сітку і нетканий матеріал розміщено по підошві та бічним стінкам приямка під фундамент, вони обгортають заповнювач зверху з нашаруванням їх кінців один на один, що міцно скріплюються. Протизсувна споруда для закріплення зсувонебезпечних схилів траншейного типу має подібну конструкцію, але влаштована вертикально. Конструкції являють собою об'ємно замкнуті системи, міцність яких визначається їх геометриєю, міцністю геосинтетичних матеріалів

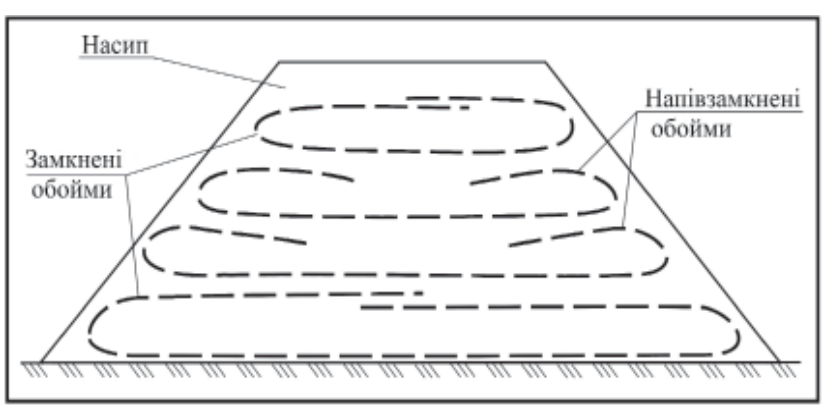

Рис. 1. Схема укладання геотекстилю

на розтяг і міцністю їх з’єднання, видом та щільністю заповнювача. Вони можуть виконувати декілька функцій, а саме: розподіляти напруги по площі, сприймати зсувне навантаження грунту в схилі, як підтримуюча споруда, виконувати функцію дренажу.

Для проведення досліджень розроблено експериментальну установку - лоток 3 жорсткими бічними стінками 3 розмірами $100 \times 20 \times 60$ см, що облаштовано пристроєм для передачі навантажень до 1000 кг на штамп. Величину та зміну зусиль у часі в зовнішньому елементі (сітці) під дією навантажень фіксували за допомогою двох датчиків зусиль. Отримані дані передавались у блок обробки і виведення інформації та записувались в окремий файл. Деформування конструкції і грунту основи контролювали за допомогою дев'яти датчиків переміщення з точністю виміру 0,01 мм.

3 врахуванням визначених характеристик грунтів моделей, їх геометричних параметрів та фізикомеханічних показників геосинтетиків проводилось моделювання роботи досліджених конструкцій на ПК з використанням програмного комплексу PLAXIS (рис. 2).

Було досліджено моделі фундаментної подушки 3 розмірами $30 \times 10,19 \times 10$ і $24 \times 5$ см. В якості заповнювача фундаментної подушки використовували

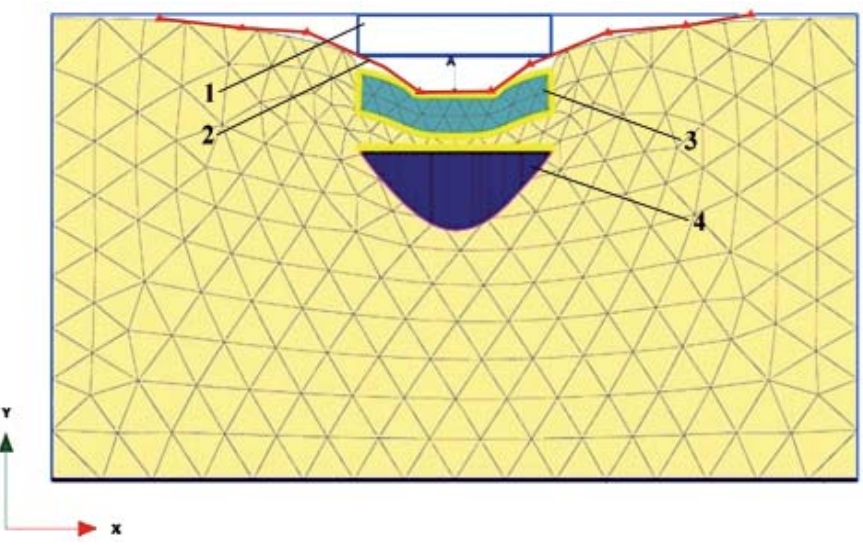

Рис. 2. Характер зусиль та деформації моделі:

1 - початкове положення фундаментної подушки, 2 - дослідні значення деформацій подушки, 3 - деформації подушки та сітки основи, визначені

PLAXIS 2D, 4 - епюра зусиль на розтяг в нижньому полотні геосинтетика 
щебінь фракції 10-20 мм або відсів. Навантаження на модель задавали ступенями від 300 до 1600 кН/м². Показники датчиків переміщень та зусиль фіксували після стабілізації деформацій.

Вважаючи на те, що геосітка працює на розтяг, а ущільнений заповнювач - на стиснення, наближено можна вважати, що під дією зовнішнього навантаження фундаментна подушка працює як плита на пружній основі. Армуюча сітка розподіляє напруги по всій площі армування, що забезпечує збільшення несучої здатності підвалин фундаменту і зменшує його деформації. В свою чергу, геотестиль виконує функцію розділяючого шару між грунтом основи і заповнювачем фундаментної подушки.

Для рішення задачі для умов досліду використовували рівняння для плити на пружній основі [7]. Співставлення переміщень умовної плити, що визначено за даними розрахунків $з$ експериментальними даними, наведено на графіку (рис. 3).

Також були досліджені моделі конструкцій протизсувних споруд двох типів. Перша - модель у вигляді виїмки траншейного типу. Під час випробувань було досліджено роботу моделей, товщина яких складала 7 і 10 см. Друга модель конструкції для закріп-лення схилів - у виді розташованих в один або два ряди вертикальних свердловин, що примикають одна до одної і заповнені щебенем фракції 5-10 мм в оболонках з тканого полімерного матеріалу високої міцності. Нижній кінець оболонки був зашитий, а верхній, після заповнення іiі ущільненим щебенем, міцно з'єднаний. На рис. 4 представлено схему протизсувної споруди.

Для аналізу напружено-деформованого стану запропонованих грунтоармованих конструкцій було записано наступні рівняння:

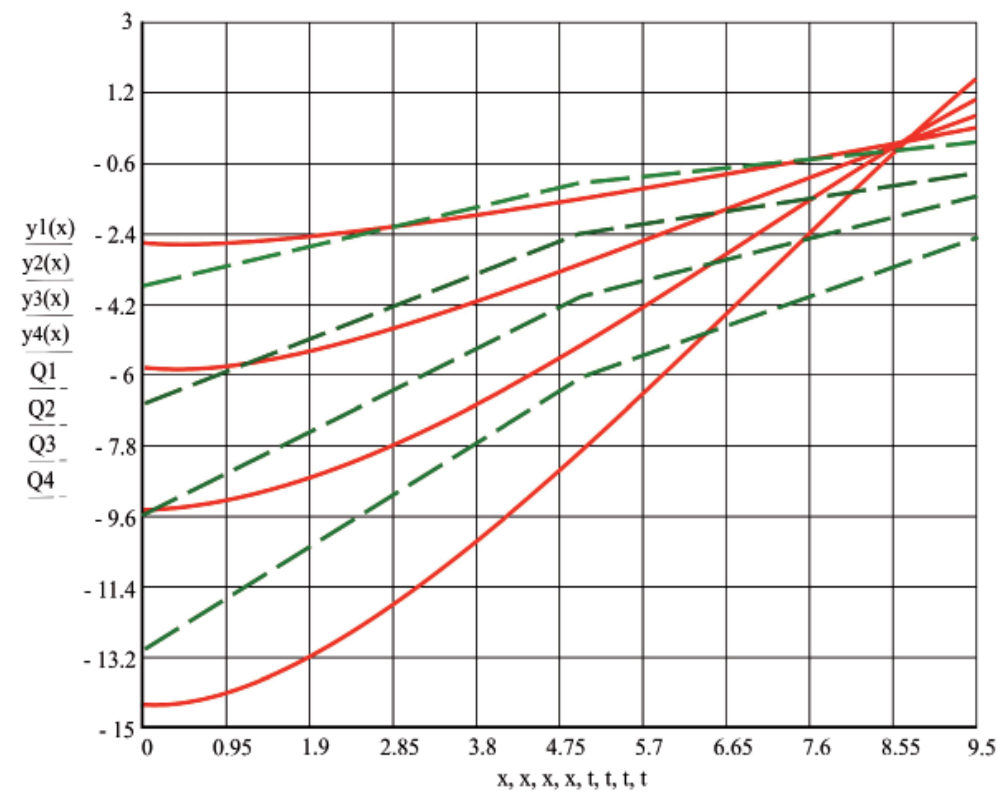

Рис. 3. Співставлення переміщень умовної плити $(---)$ - визначено по формулі,

$$
\begin{aligned}
& \frac{d^{2}}{d x^{2}}\left(D(x) \frac{d^{2} y_{1}}{d x^{2}}\right)+m_{c} b_{c} \varphi_{1}(x) y_{1}=b_{c} \varphi_{1}(x) \delta(t) \\
& \frac{d^{2}}{d x^{2}}\left(D(x) \frac{d^{2} y_{2}}{d x^{2}}\right)+b_{c} \varphi_{2}(x) y_{2}=0
\end{aligned}
$$

де $y_{1}$ i $y_{2}$ - загальне переміщення осі вертикальної грунтоармуючої конструкції на ділянці вище та нижче поверхні ковзання; $m_{c}-$ коефіцієнт, що враховує стійкість грунтів, що межують 3 грунтоармуючою спорудою нижче по схилу, $m_{c}=2,0$, коли коефіцієнт стійкості грунтів $>1,5$. Коли коефіцієнт стійкості грунтів близько $1,0, m_{c}=1,0$. При коефіцієнті стійкості грунтів в межах 1,0-1,5 величина тс приймається за інтерполяцією; $b_{c}$ - ширина грунтоармуючої конструкції; $D(x)$ - жорсткість грунтоармуючої конструкції, що змінюється по глибині; $\delta(t)$ - переміщення зсуву в часі; $\varphi_{I}(x)$ реакція грунту на переміщення грунтоармуючої конструкції в зсувному грунті; $\varphi_{2}(x)$ - реакція грунту на переміщення грунтоармуючої конструкції в стійких грунтах нижче поверхні ковзання.

Залежність реакції грунту на переміщення грунтоармуючої конструкції в зсувних та стійких грунтах, як правило, задають у вигляді:

$\varphi_{1}(x)=\frac{k_{o}}{\left(1+a_{1} x\right)^{4}}, \quad \varphi_{2}(x)=\frac{k_{h}}{\left(1+a_{2} x\right)^{4}}$.

Підставивши в систему рівнянь (1) залежності (2), для постійної по глибині грунту жорсткості грунтоармуючої конструкції $D(x)$ отримаємо систему рівнянь у вигляді:

$$
\begin{gathered}
\frac{d^{4} y_{1}}{d x^{4}}+\frac{m_{c} k_{o} b_{c} y_{1}}{D\left(1+g_{1} x\right)^{4}}=\frac{\delta k_{o} b_{c}}{D\left(1+g_{1} x\right)^{4}} . \\
\frac{d^{4} y_{2}}{d x^{4}}+\frac{a_{h} b_{c} y_{2}}{D\left(1+g_{2} x\right)^{4}}=0 .
\end{gathered}
$$

Рішення (3) та (4) отримаємо в аналітичному вигляді:

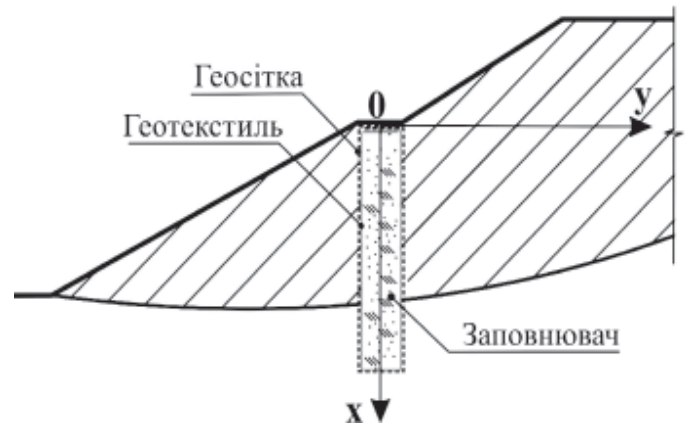

Рис. 4. Схема конструкцій для закріплення схилів 


$$
\begin{gathered}
y_{1}=\frac{\delta}{m_{c}}+\left(1+g_{1} x\right)^{\alpha_{1}}\left[\begin{array}{l}
A_{1} \cos \beta_{1} \ln \left(\left(1+g_{1} x\right)\right)+ \\
+A_{2} \sin \beta_{1} \ln \left(\left(1+g_{1} x\right)\right)
\end{array}\right]+ \\
+\left(1+g_{1} x\right)^{\alpha_{2}}\left[\begin{array}{l}
A_{3} \cos \beta_{2} \ln \left(\left(1+g_{1} x\right)\right)+ \\
+A_{4} \sin \beta_{2} \ln \left(\left(1+g_{1} x\right)\right)
\end{array}\right] \\
y_{2}=\left(1+g_{2} x\right)^{\alpha_{3}}\left[\begin{array}{l}
B_{1} \cos \beta_{3} \ln \left(\left(1+g_{2} x\right)\right)+ \\
+B_{2} \sin \beta_{3} \ln \left(\left(1+g_{2} x\right)\right)
\end{array}\right]+ \\
+\left(1+g_{1} x\right)^{\alpha_{4}}\left[\begin{array}{l}
B_{3} \cos \beta_{4} \ln \left(\left(1+g_{2} x\right)\right)+ \\
+B_{4} \sin \beta_{4} \ln \left(\left(1+g_{2} x\right)\right)
\end{array}\right]
\end{gathered}
$$

де $\alpha_{1}, \alpha_{2}, \alpha_{3}, \alpha_{4}$ ma $\beta_{1}, \beta_{2}, \beta_{3}, \beta_{4}$ - дійсні алгебраїчні форми комплексного кореня $\mu_{I i}$ i $\mu_{2 i}$ :

$$
\begin{gathered}
\mu_{1 i}= \pm \sqrt{1.25 \pm \sqrt{1-\frac{m_{c} k_{o} b_{c}}{D g_{1}^{4}}}}+1.5, \\
\mu_{2 i}= \pm \sqrt{1.25 \pm \sqrt{1-\frac{a_{h} b_{c}}{D g_{2}^{4}}}}+1.5 . \\
\mu_{11,2}=\alpha_{1} \mp \beta_{1} i ; \mu_{13,4}=\alpha_{2} \mp \beta_{2} i ; \\
\mu_{21,2}=\alpha_{3} \mp \beta_{3} i ; \mu_{23,4}=\alpha_{4} \mp \beta_{4} .
\end{gathered}
$$

3 фізичних властивостей деформування грунтоармуючої конструкції маємо наступні граничні умови задачі:

$$
\begin{array}{ll}
x=0 ; & y_{1}^{\prime \prime}=y_{1}^{\prime \prime \prime}=0, \\
x=h ; & y_{1}=y_{2}, y_{1}^{\prime}=y_{2}^{\prime}, \\
& y_{1}^{\prime \prime}=y_{2}^{\prime \prime}, y_{1}^{\prime \prime \prime}=y_{2}^{\prime \prime \prime}, \\
x=l ; & y_{2}^{\prime \prime}=y_{2}^{\prime \prime \prime}=0 .
\end{array}
$$

Взявши похідні з рішень (5) та (6) і підставивши їх в граничні умови задачі (9), отримаємо вісім алгебраїчних рівнянь для визначення постійних $A_{i}$ та $B_{i}$. Рішення алгебраїчних рівнянь проводилось на ПК з використанням програмного комплексу «Mathcad».

Рішення (5) та (6) з визначеними постійними $A_{i}$ та $B_{i}$ дозволяють визначити зусилля в геосітці.

Співставлення результатів експериментальних досліджень моделі протизсувної споруди для закріплення схилів першого типу 3 рішенням, отриманим з рівнянь (5) та (6), показано на рис. 5.

На рис. 6 показано одну 3 можливих схем закріплення зсувонебезпечного схилу вертикальними свердловинами 1, що улаштовано на схилі перпендикулярно напрямку току грунтових вод 2 в один ряд. При цьому вони перетинають поверхню ковзання зсуву 3 на позначках іï
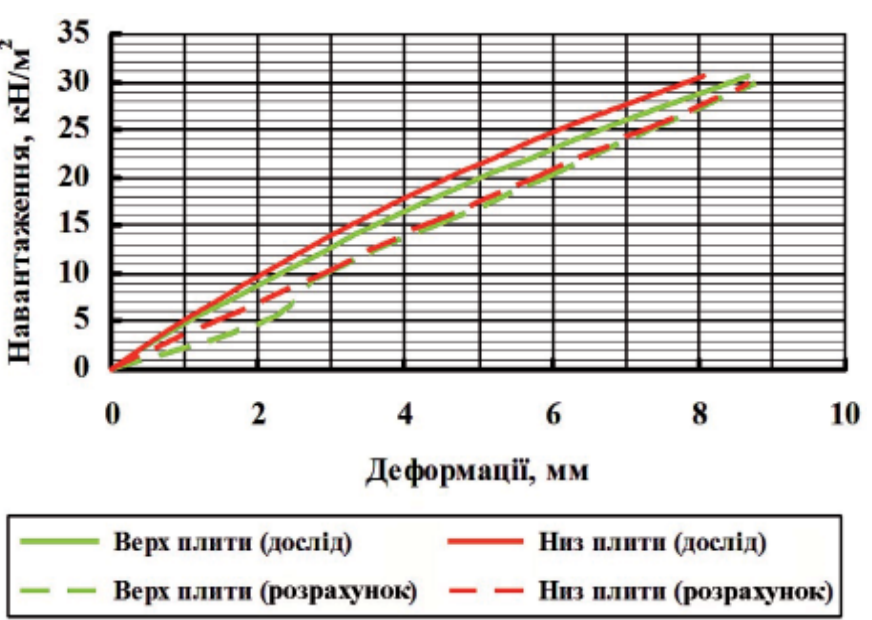

Рис. 5. Співставлення результатів дослідження моделі конструкції для закріплення схилів 3 щебеню товщиною $\delta=10$ см 3 рішеннями 3 рівнянь (5) та (6)

мінімальних похилів. Свердловини з'єднано з дренажем на укосі 4 за допомогою дренажних труб 5. Свердловини містять геосітку 6, геотекстиль 7, заповнювач 8 .

Відстань між свердловинами, з яких відводиться грунтова вода у дренаж на укосі і положення позначки під'єднання до них дренажних водовідвідних труб, визначають на підставі фільтраційних розрахунків [8].

\section{РЕКОМЕНДАЦІЇ ЩОДО РОЗРАХУНКУ РОЗ- РОБЛЕНИХ ПРОТИЗСУВНИХ СПОРУД}

На основі проведених лабораторних і чисельних експериментів встановлено, що найбільша величина зусилля на розтяг в грунтоармуючих конструкціях виникає в геосітці зі сторони схилу на рівні, близькому до поверхні ковзання. Діюче зусилля повинно бути не більше величини міцності на розтяг сітки і геотекстилю. Розрахунки проводять на основі виразу:
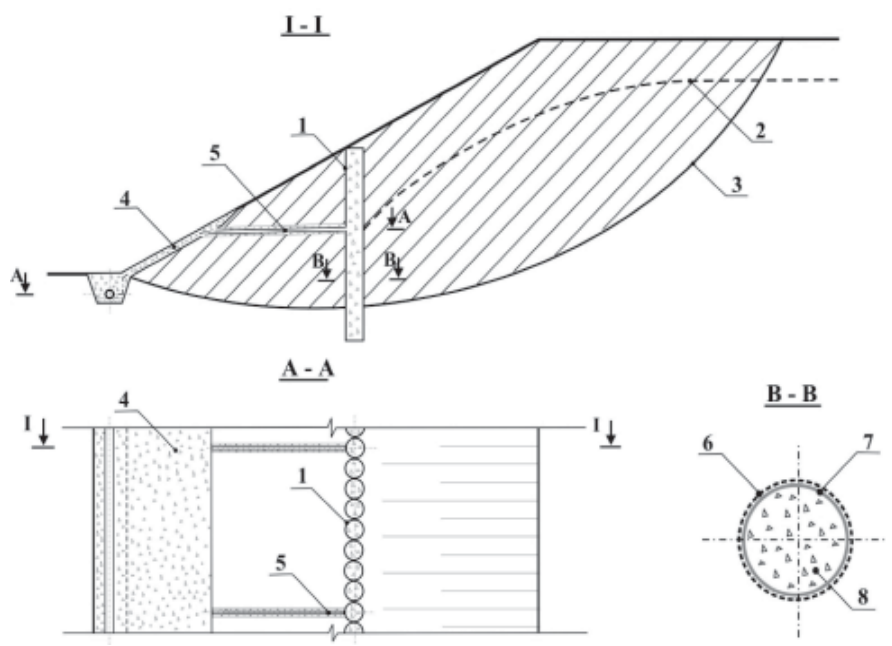

Рис. 6. Схема розташування протизсувної споруди на схилі 


$$
F_{3} \leq \frac{\gamma_{c}}{\psi \gamma_{n}} R_{3},
$$

де $R_{3}$ - сумарна міцність на розтяг сітки і геотекстилю, що визначають за технічними характеристиками чи за експериментальними даними; $F_{3}-$ зусилля на розтяг, що визначається на основі рішень (5) та (6); $\gamma_{0} \gamma_{w} \psi$-коефіцієнти, значення величин яких наведено в [9].

\section{ВИСНОВКИ ТА ПЕРСПЕКТИВИ} ПОДААЬШИХ ДОСАІДЖЕНЬ

1. На основі проведених досліджень встановлено, що конструкції з оболонкою із міцного геосинтетичного матеріалу, що щільно заповнені щебенем, гравієм або відсівом, сприймають вертикальні чи горизонтальні навантаження i розподіляють їх по площі чи передають зсувний тиск грунтів на стійкі грунти.

2. Проведено серію дослідів для кількісного оцінювання малорозмірних моделей грунтоармованих конструкцій під дією статичних вертикальних чи горизонтальних навантажень. Встановлено залежності характеру пружно-деформованого стану конструкцій від геометричних розмірів, модулів пружності геосинтетиків та схеми з'єднання матеріалу.

3. Запропоновано математичну модель роботи грунтоармованих конструкцій під дією статичних вертикальних чи горизонтальних навантажень та виконано моделювання роботи грунтоармованих конструкцій в основах споруд в двовимірній постановці iз застосуванням програмного комплексу PLAXIS 2D.

4. Проведено серію розрахунків для оцінки пружно-деформованого стану грунтоармованих конструкцій на основі запропонованої математичної моделі та виконано співставлення їх 3 експериментальними даними.

5. Для підтвердження отриманих результатів доцільно провести дослідно-виробничу перевірку роботи запропонованих конструкцій в натурних умовах.

\section{БІБЛІОГРАФІЧНИЙ СПИСОК}

1. Армовані основи будівель та споруд / [М.Ф. Друкований, С.В. Матвєев та ін.]. Вінниця: УНІВЕРСУМ, 2006. - 235 с.

2. Корчевський Б.Б. Горизонтальні армовані основи під фундаменти будівель / Б.Б. Корчевський. - Вінниця: УНІВЕРСУМ, 2004. - 120 c

3. Приходько А.П. Экспериментальные исследования грунто-армированной конструкции / А.П. Приходько // Мат-лы научно- технической конф. с междунар. участием Палеотип. - М., 2013. - С. 68-72.

4. Мирсаяпов Н.Т. Оценка прочности и деформативности армированных грунтовых оснований / Н.Т. Мирсаяпов. - М.: Геотехника, 2010. - №4. - С. 58-67.

5. Матеріали геосинтетичні в дорожньому будівництві: ВБН В.2.3-2-544:2008. - [Введ. в дію 2008-10-14]. - Київ: Укравтодор, 2008. - 106 c.

6. Empfehlungen für Bewehrungen aus Geokunstoffen - EBGEO / Нем. общество по геотекстилю. - 1997.

7. Флорин В.А. Основы механики грунтов / В.А. Флорин. - А.-М. : Стройиздат, 1959. T.1. - 358 c.

8. Олейник А.Я. Фильтрационные расчеты вертикального дренажа / А.Я. Олейник. - Киев: Наукова думка, 1978. - 202 с.

9. Інженерний захист територій, будівель і споруд від зсувів та обвалів. Основні положення: ДБН В.1.1-46:2017. - [Чинний від 2017-1101]. - Київ: ДП «Укрархбудін-форм», 2017. $-\mathrm{IV},-47 \mathrm{c}$. 